\title{
ICT and Competences Connected with the Subject Environmental Education in Primary School
}

\author{
Robert Repnik \\ Faculty of Natural Sciences and \\ Mathematics, Physics Department, \\ University of Maribor, \\ robert.repnik@uni-mb.si
}

\author{
Vladimir Grubelnik \\ Faculty of Electrical Engineering and \\ Computer Science, \\ University of Maribor, \\ vlado.grubelnik@uni-mb.si
}

\begin{abstract}
In Slovene educational curriculum the subject Environmental education is taught from the first to the third level of primary school (pupils' age between seven and nine). The goal of this subject is not merely acquiring basic facts about the world around us; it is rather more important for students to gain specific and general competences for lifelong learning. Competences consist of different kinds of knowledge, skills and abilities, as well as personality attributes (character, behaviour, convictions, etc.). They can be trained only by appropriate didactic methods which force students' activity. Teachers must themselves possess required competences in order to guide children in right direction. Therefore, the need for frequent thorough training of teachers often appears. Here we discuss in particular elearning materials for the $3^{\text {rd }}$ grade Environmental education developed within our national project two years ago. Digital literacy is needed among other teacher's competences when using e-materials in school. We will also focus on a list of generic competences tightly connected with the natural sciences.
\end{abstract}

\section{Introduction}

Natural and social sciences, technics and complexity of everyday life are nowadays developing too quickly to be followed in education in all their integrity and diversity. In order to solve this problem, the most important topics have to be selected and appropriate didactic strategies are necessary. Aspects of social and natural sciences are introduced to students as early as in the first years of regular education. As an example, we focus here on the subject Environmental education, which is taught from the $1^{\text {st }}$ to the $3^{\text {rd }}$ grade of primary school. Its goal is giving students the basic knowledge about the world around us and training them in specific and general competences for functioning properly in the modern society. The part of any competence is not only the formal knowledge, but also skills and personal characteristics (attitudes, habits, convictions, etc.). The subject Environmental education also points to everlasting ethical questions: altruism and tolerance, relation to nature and sustainable development, etc. On the other hand, science brings new findings about the surrounding world and new technological achievements, which are difficult to follow even for experts, not just for teachers. However, it is obvious that the children are fairly susceptible to acquiring experimental and other skills[1] as well as learning from ICT (Information Communication Technology) sources, such as computer web pages. Therefore, combining experiments with ICT may be a very successful way of learning natural (and partly social) sciences to a satisfactory depth. For this reason e-learning materials for the $3^{\text {rd }}$ grade subject Environmental education were created on web pages in 2008 in the frame of the national project[2].

Various specific competences that should be trained and developed within individual topics (for instance, simple systematic observation and measurement in physics topics) are prescribed in the national curriculum. Here, we list the 8 key competences from the European legislation [3] which every citizen should acquire during regular education:

1) Communication in the mother tongue

2) Communication in foreign languages

3) Mathematical competence and basic competences in science and technology

4) Digital competence

5) Learning to learn

6) Social and civic competences

7) Sense of initiative and entrepreneurship

8) Cultural awareness and expression

There exist several other lists of competences which are either more subject specialized(for instance, nature science competences for individual sciences) or have a narrower meaning than competences from above list. For example, we found the Mayer list of competences from Australian council [4] very suitable since it includes several 
well defined competences. Among them, we may focus on the following 14 competences which are particularly connected with natural sciences:

1) Ability to collect information

2) Ability to analyze the literature and organize information

3) Ability of interpretation

4) Ability of drawing conclusions

5) Ability to learn and solve problems

6) Transfer of theory into practice

7) Using mathematical ideas and techniques

8) Adaptability to new situations

9) Care for quality

10) Ability of individual and team work

11) Organization and planning activities

12) Verbal and writing communication

13) Inter-personal interaction

14) Safe operation

In this paper we describe the contents of $3^{\text {rd }}$ grade subject Environmental education, its connection with key competences and the corresponding e-learning materials [5]. Furthermore, we discuss the limitations in the use of this method, as well as our plans, how to circumvent these difficulties. Among other problems we discuss the need for permanent training of primary school teachers, so that they keep following the ever-growing complexity of science and technics. We focus in particular on the importance of natural science competences: we treat them from the aspect of 14 generic competences listed above.

\section{Contents of the $3^{\text {rd }}$ grade subject Environmental education}

Since the age of students at this level is about nine the concepts of environmental education must be learned at the level of understanding concrete operations. The subject contains the following topics which include both natural and social science themes [6]:

- Who we are and what we are doing: In this topic students find the importance of: school and knowledge; production and goods; work, profession and leisure activities; and money.

- Me and you, you and us: wants to teach students about cooperation and tolerance between people and why help and solidarity are necessary in the society.

- Where we are living: shows students the institutions like post, shops, galleries, banks, museums and churches. The second part is dedicated to the neighbouring states and citizens.

- Slovenia, my country: presents the fundamental information about Slovenia,
Slovenian money and symbols of the Slovenian country.

- Celebration wants to teach students about personal celebration, work-free days and holidays in Slovenia and other celebrations that are not work-free days but are very important for the society (e.g. international Women's Day, Earth's Day, World Book Day, and Children's Day).

- Once upon a time wants to show changes through time in the place we are living; about the history, culture and people's customs; songs and games; fairytales, stories and fables.

- Me and the nature explains the position of man in the surrounding environment. Topics about animals and plants want to influence individuals to behave properly.

- Me and health wants to influence the nutrition habits of students. Students must know which food is healthy and its benefits.

- Man and nature is an extension of the topic Me and the nature. Value of water and effects of pollution of all kinds are presented. Important topic is the problem of smoking. We don't want our children to start smoking.

- Illnesses wants to teach students about the symptoms of illnesses and the importance of following doctors prescriptions.

- Protection against illnesses teaches personal hygiene and microbes.

- What I am able to do shows what can be done from the paper, how to sew a button, how to apply a patch, how to treat of iron panel and wires, and garbage collection.

- Things change shows the changes of goods exposed to air, water and light.

- Air shows the properties of air and the importance of oxygen for living organisms.

- Movement shows how bodies move under the influence of force in the air and in water.

- Light shows the importance of illumination and the properties of (sun)light. Especially prevention from sunburns is important.

- Sky describes virtual movement of the Sun; night sky; and Polaris.

- Weather describes rain, thunder, snow, wind and temperature.

- Sound is for describing the properties of sound and how sound is generated. How fast the sound travels in different media.

- Time is for teaching the relationships between days, hours, and minutes; how time is measured (digital and analog watch) and what are the proper timelines of events. 
- Looking around teaches about waste and waste treatment

- Traffic teaches types of traffic and influence of traffic on people

- Transmission of data and information teaches about communication devices and their use (phone, GSM and internet)

- Data storage is meant to teach about storing data to magnetic, optical and electronic media

- Things and its parts teach that almost all appliances are built from parts. Shows how parts are connected and why it is important to distinguish the parts of products.

It is evident that some topics are more focused to social sciences and other to natural sciences. It is also clear that all of the eight key competences above except for communication in foreign languages are connected with the given topics.

\section{E-learning materials}

The developed e-learning materials for $3^{\text {rd }}$ grade Environmental education cover all didactics goals prescribed in the national school plan for this level. For instance in 6 topics connected with physics (Movement, Light, Sky, Weather, Sound and Time) the basic idea of e-materials is to guide teachers and pupils to repeat the presented experiments in equal way and also to encourage them to perform their own variants of the experiments. Thus the active forms of student's work are stressed what leads to strengthening of several specific competences for natural sciences as well as some key competences, such as "learning to learn". All the topics are presented by various means: figures, sound, films, explanation text, motivation questions and interactive knowledge tests (interactive elements) "Figure 1".

The representation structure for all topics and experiments is the same. Each topic is divided into sections corresponding to the learning goals. There are several explanation text boxes, presentations of different kinds (sound and video animations, video films, images). There is a mascot - the owl that personifies the wisdom - who leads the pupil through the e-learning. Furthermore, there are other common icons for all topics that activate certain actions (typical signs), for instance the icon for "discover", which encourages the pupil to see what will happen in some natural situation. There are also interactive elements that test the pupils' understanding of topic immediately. The final knowledge test is provided for each topic.

The 25 topics listed above are organized into 10 groups of topics in the e-learning materials. The largest $8^{\text {th }}$ group contains topics from What I am able to do to Time (thus including all physics topics) $[5,6]$.
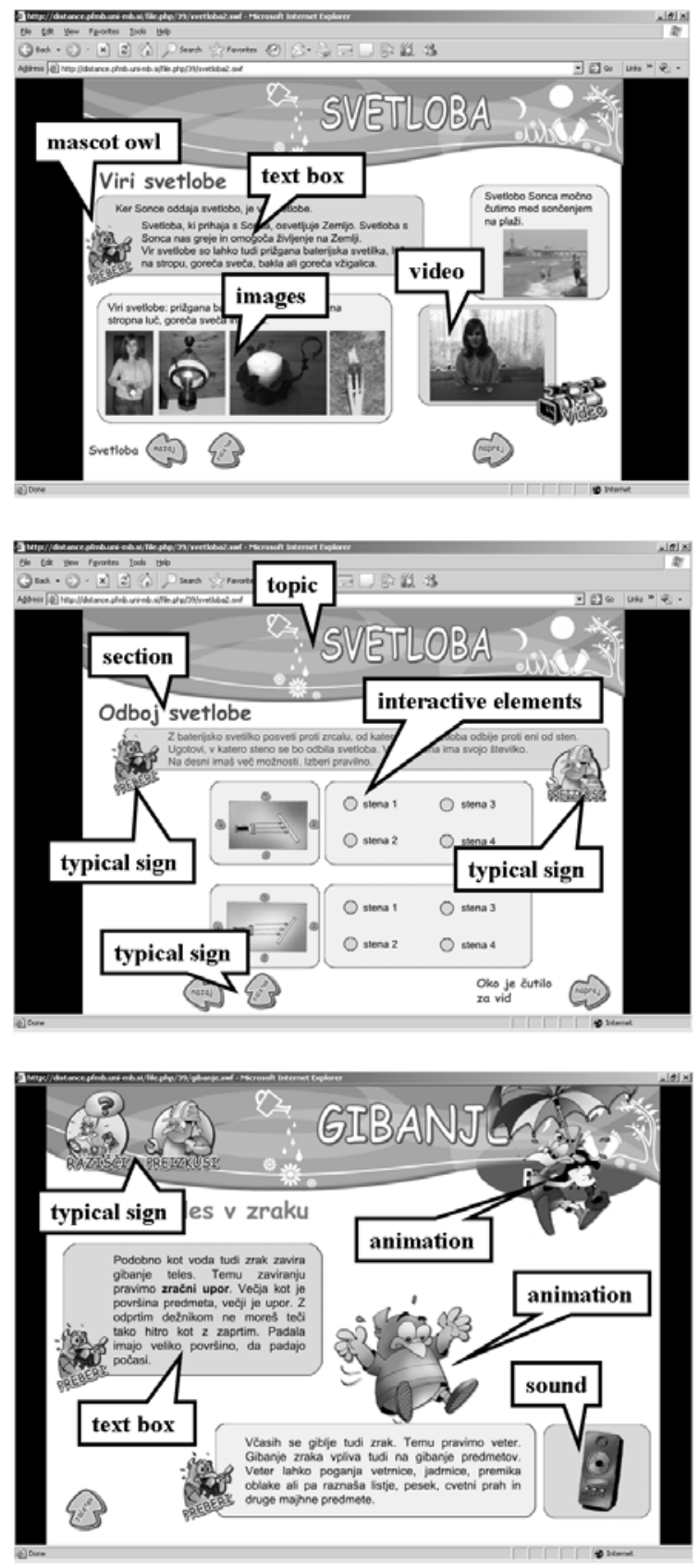

Figure 1. Typical screen elements in topic presentations.

The use of e-learning materials in school practice may present several dilemmas for teachers. First of all, teachers have to develop their own digital competence to a satisfactory level. Next, some contents in these materials may be novel to the teacher, so he/she must study the materials well before using them in school. And most important, teachers have to select the best didactic approach (frontal or group work, discussing the results of tests or not, partially home work for students or not, etc.) according to the digital competence of children, their starting knowledge about the topic, availability of computers in school, etc. Therefore, we decided to 
perform a mini-investigation about the use of these e-learning materials in school practice.

\section{Experience in using e-learning materials}

First, we conducted a preliminary didactic experiment with primary school teachers (teaching Environmental education) on the use of e-learning materials just for 6 physics topics mentioned above [7]. There was no cooperation of pupils at this stage. At the end of the course teachers wrote seminar which content was the preparation of the one class lesson connected to one of the 6 topics. The response of teachers on the experiment on e-learning materials was very positive. Among their positive comments were the following ones:

1) It is encouraging that someone at all started work on e-learning materials for this level[8,9].

2) The modern didactics principles are appreciated.

3) Since the pupils, their parents and the school manager forced teachers all the time to use ICT more frequently the new elearning materials are welcome.

4) The teachers for this level have commonly too shallow knowledge about natural sciences and also have too few ideas for experiments and thus e-learning is a good guide for them.

5) A good set of multimedia elements is given in e-learning materials.

6) All pedagogic goals can be fulfilled with additional help of e-learning; for instance when the weather is bad and prevents some experiments in nature, at least there is a corresponding simulation on web page.

In subsequent didactic experiments teachers first learned about e-learning materials, and then they used them in practice, in their classes. Three main conclusions were drawn:

1) Pupils were enthusiastic about conducting experiments by following instructions of elearning materials.

2) The acquired knowledge was not satisfactory since they didn't work systematically.

3) The textual explanations seemed to be too lengthy in regard to reading skills of pupils.

Consequently, the need for slightly smaller pupils' self-initiation and more organized teachers' guidance became evident. Teachers themselves appealed the need for additional courses in e-learning materials, so that they can be more self-confident in leading the classes with this technique. In particular, the explanation texts on web pages should be shorter, and the teachers should give oral explanation of the topic and experiment instead. Now, the project on revision of the e-learning materials according to the teachers' recommendations is going on.

In further investigations (mainly on 6 physics topics, but we believe that most findings hold for other topics, too) with informal cooperation of teachers in testing partially upgraded e-materials we received some additional teachers' comments and some of them indicate problems or positive suggestions [10]:

1. All the mentioned 6 topics should be partially covered by e-learning materials in a suitable way: either by performing the experiments suggested by materials (without going through all details in materials), or just using the e-materials while other experiments (not those in ematerials) are conducted, or doing both (going through all the reading, simulations, animations and tests in the e-materials and conducting all described experiments).

2. The problem appears if the school is equipped with too few computers. If the pupils sit at computers in pairs, all of them should take equal effort. The positions of the pupils in pairs must be exchanged, so that every pupil does some typing on computer keyboard instead of being bored and just watching what his/her partner is doing. It's not good if the abilities of the pupils in the same pair are too different.

3. It is quite difficult for the teacher to simultaneously take the overall control in the classroom and help individual pupils (either in understanding the text or user operations in e-materials or in performing the real experiment) because of different pupils' abilities. Therefore, at least a part of the teaching with e-learning materials must be in a frontal form. The frontal work is also more appropriate for checking pupils' answers in tests in e-materials.

4. Some topics are appropriate not only for $3^{\text {rd }}$ grade but also for lower or higher classes, from $1^{\text {st }}$ to $5^{\text {th }}$ grade.

5. E-materials are very convenient to use in the case of teacher's supply (i.e., when the class teacher is absent), particularly when the supplementing teacher who teaches some other special subject in higher classes is not familiar with natural sciences.

6. It would be a good idea if two teachers of the $3^{\text {rd }}$ classes at the same school cooperate in some kind of exchange of classes in the following way. Each of them takes three of the six physics topic and presents them with e-learning materials in both classes. This would be probably interesting for pupils. This would not be against the rules because this would only a part of adopting the material, not evaluation of pupils. 
7. Tests are rarely used on computers. Teachers much rather test the knowledge of their students traditionally. Teachers also said that 45 minutes, which are the typically available for the lessons, does not permit them to $\log$ in all users and use electronic tests. Guests on the other hand cannot use electronic tests. E-learning materials can be used in multimedia-equipped classroom but tests need computer classroom and this presents an additional constraint.

It is evident from the teachers' comments that they often feel uncertain when using new didactic tools in school practice. They should participate regularly in the seminars or workshops where the corresponding didactic strategies are learned together with new teaching tools, such as e-learning materials.

LMS Moodle gathers the statistics of visiting individual topics. The time dependence of the frequency of visits is of course correlated to the teaching annual periods. The comparison of the frequency of visits for different topics is more interesting. If we group the topics which are definitely of either natural or social science types into two categories we see that social sciences have 2889 visits and natural sciences 2903 visits in the period November 2008 - May 2010. Statistically we could say that they are even. But if we add engineering topics and human body to the natural sciences, we get much higher frequency of visits in favour of natural sciences: 5181 [6].

In the current national project "Development of Science Competences" authors from different institutions (mostly faculties with pedagogical/didactic programs) cooperate with dozens of school teachers from the first years of primary schools to secondary schools (and even a few kindergartens are included) [11]. Authors prepare didactic materials that should give the directions for new didactic strategies; teachers apply these suggestions by testing the materials in school. In this way, both teachers' and students' competences can be developed simultaneously. But this is just the first important step for improving teachers' educational competences. The findings of the national projects should be incorporated into educational faculty programs as well as in the series of workshops for teachers.

\section{Natural science topics and generic competences}

Many topics listed above refer to biological or physical phenomena. For instance, there are 6 topics directly connected with physics (although the children have no idea of physics as a subject): movement, light, sky, weather, sound and time. These topics are extremely important for the development of some physics concepts later when the students grow older and learn physics as separate school subject. Many physics concepts are accompanied with the misinterpretations which are burned in the human's intuition as the result of everyday experience. Thus it is very useful to start fighting against such misconceptions as early in the education as possible. A typical example is deficient understanding of the first and second Newton's laws. The topic movement in the $3^{\text {rd }}$ level subject Environmental education gives examples of the influence of forces on the change of the body's movement at the qualitative level, including friction forces. This may help students to gain understanding that the body cannot just stop, without any force to cause that. Of course, the teacher of the subject Environmental education should know the basic physical principles as well (although he or she need not be the specialist for physics); otherwise the teachers is not able to guide the young students safely away from the traps of the misunderstandings.

But training natural science competences in the frame of some topics of Environmental education is even more important than gaining some basic formal knowledge in natural sciences. We discuss some of the above mentioned 14 generic competences in connection with the e-learning materials (the reader will recognize that most of them are connected with social sciences as well). We stress that the students can gradually develop these competences only through the learning process in the long term (taking several years). On the other hand, teachers should already have these competences (or they are forced to acquire them in as short time as possible). Therefore, in the following discussion of generic competences that are particularly developed by using our e-learning materials we will mean only the students' competences. Since the appropriate personal characteristics are the essential part of every competence, we shall mention them with regard to the following list of generic competences.

1) Ability to collect information. In our case this is mostly acquiring information from the web pages and this generic competence is connected with the digital literacy. Collecting information from e-learning materials is technically different from using printed text because of the active interaction tools between the user and computer. Personal characteristics: diligence, self-confidence (the latter characteristic is necessary when the student finds a mistake in information).

2) Ability to analyze the literature and organize information. Analyzing information in elearning materials can be seen in several ways, for instance, by students' comparison of their own experiments with those shown in materials. Personal characteristics: diligence, frankness (the student must be aware of the possibility that he/she can make mistakes).

3) Ability of interpretation. In particular, animations and the films of real experiments in e-learning materials require and develop the sense for interpretation. The sketches of 
natural phenomena (for instance the sketch of forces acting on the moving body) also require some interpretation. Personal characteristics: criticalness combined with the appropriate measure of self-confidence.

4) Ability of drawing conclusions. This competence is strongly connected with the ability of interpretation. One aspect of drawing conclusions can be mentioned here: when the student tries his/her own experiment and realizes that the experiment agrees with the one shown in the learning material, he/she may gain some confidence that his/her work is correct. The interactive tools (quick tests) for checking the students' understanding of the studied material actually ask for the students' correct interpretation and conclusions about the animations, learning text, films, etc. Personal characteristics: criticalness combined with the appropriate measure of self-confidence.

5) Ability to learn and solve problems. Understanding and repeating experiments is the best way to learn (and to learn learning, see the fifth key competence mentioned in the Introduction section) the concepts of natural phenomena, at least at the cognitive level of concrete mental operations. Problem-solving in these materials is stimulated, for instance, in the action "discover" described above, and in answering the test questions. Personal characteristics: diligence, self-confidence, criticalness, sometimes a good sense for imagination.

6) Transfer of theory into practice. This generic competence is stimulated by the hints that the students should repeat the shown experiments, or even think of their own variants. Next, the bare content of many topics indicates the connection between the theory and everyday practice. Personal characteristics: love for practical aspects and applications.

7) Ability of individual work and organization and planning activities. It is sensible to consider these two generic competences together. E-learning materials are planned for the student's individual work. But the teacher can organize the work in pairs or small groups (three students at one computer) to practice and develop other competences, such as verbal communication, etc. Personal characteristics: sense of initiative and entrepreneurship (see the seventh key competence in the Introduction section), diligence, self-confidence, orderliness, some kind of modesty (to be aware of the limits of his/her capabilities in order to make a realistic working plan), etc.

Let us now turn to teacher's competences. There is no doubt that the teacher's example (behaviour, manners, working methods) is worth much more than many words. As an example we take the first generic competence in our list. The teacher should show his/her own approach of collecting information, instead of spending time for lengthy explanations of this competence. For instance, the teacher should compare the information from two or three different sources of various kinds (web pages, printed textbook, scientific article). He/she should briefly comment possible differences in the data from different sources: which data are more probable and reliable, is anywhere an evident mistake, are the differences just apparent and not real, and similar. The teacher must be aware that the students notice very quickly his/her characteristics, convictions and attitudes in relation tom the learning subject. In our opinion, perhaps the most important thing to advise the teacher is to show a reasonable combination of self-confidence and modesty with cautiousness (in the fields where his/her knowledge is shallow). It is not easy for the teacher to appreciate all the findings about training generic and other competences since the experience in this field is the result of extensive didactic research. In order to help the teachers of primary in secondary school (at least for natural sciences) to train students' competences, in the frame of the project "Development of Science Competences" we also plane to prepare the handbook with concise didactic recipes for teachers. The handbook will be the results of the gathered experience and results of testing several new didactic materials in school practice.

\section{Conclusion}

We have found that the e-learning materials concerning the subject Environmental education in the $3^{\text {rd }}$ grade of primary school can be an appropriate and interesting way of improving the pupils' understanding the basic concepts of natural and social sciences. In order to accomplish this, there is a need for additional courses for teachers in using these web pages. More generally, teachers should become aware of specific and generic competences that their students must develop in order to be successful in modern society.

\section{Acknowledgement}

We greatly acknowledge the support of the Ministry of Education and Sport of Republic of Slovenia and the European Social Fund in the frame of the projects "Development of Natural Science Competences", No. 3311-08-286011 at the Faculty of Natural Sciences and Mathematics, University of Maribor. 


\section{References}

[1] I. Gerlič, Metodika pouka fizike v osnovni šoli, Faculty of Education, University of Maribor, Maribor, 1991 (in Slovene)

[2] M. Krašna, I. Gerlič, K. Skala and T. Skala, "Intelligent graphics interfaces in the distance education", in: $\mathrm{P}$. Biljanović (ed.), K. Skala (ed.), MIPRO 2005: 28th international convention, May 30 - June 03, 2005, Opatija, Croatia: proceedings, MIPRO, Rijeka, 2005, pp. 291-294.

[3] Key Competences for Lifelong Learning, available at: http://europa.eu/legislation_summaries/ education_training_youth//ifelong_learning/c11090_en.ht m (25. May 2011).

[4] Australian Education Council, Young people's participation in post-compulsory education and training, Report of the Australian Education Council Review Committee (1991), available at: http://www.voced.edu.au/docs/dest/TD_LMR_85_658.pdf (25. May 2011).

[5] E-learning materials for subject Environmental education, February 2009, Maribor (in Slovene), available at: $\quad$ http://distance.pfmb.uni-mb.si/course/ view.php?id=39 (25. May 2011).

[6] R. Repnik and B. Bedrač, "Application of e-learning material: environmental studies for $3^{\text {rd }}$ grade of primary school", Central European Conference on Information and Intelligent Systems 2010, September 22-24, 2010, Varaždin, Croatia: proceeding, Faculty of Organization and Informatics Varaždin, Varaždin, 2010.

[7] M. Krašna and T. Bratina, "Trends of e-learning in the education of teachers",in: The Fifth International Conference on Informatics, Educational Technology and New Media in Education, [Sombor, 2008], Infomedia, Sombor: Faculty of Education, 2008, pp. 65-69.

[8] R. Repnik, V. Vajngerl and M. Krašna, "Virtual learning environments", in: M. Čičin-Šain (ur.), I. Turčić Prstačić (ed.) and I. Sluganović (ed.), MIPRO 2006: 29th international convention, May 22-26, 2006, Opatija, Croatia: proceedings, MIPRO, Rijeka, 2006, pp. 92-94.

[9] R. Repnik, Z. Bradač, S. Kralj and M. Krašna, "Presentation of liquid crystals' structure and its defects for educational purposes", in: B. Aurer (ed.), D. Kermek (ed.), IIS 2003: 14th International Conference on Information and Intelligent Systems, September 24-26, 2003, Varaždin, Croatia: proceeding, Faculty of Organization and Informatics Varaždin, Varaždin, 2003, pp. 121-128.

[10] R. Repnik, M. Ambrožič, M. Krašna and V. Grubelnik, "Teachers experiences and recommendations about using e-learning materials in primary school", in: B. Aurer (ed.), D. Kermek (ed.), Central European Conference on Information and Intelligent Systems 2009, September 23-25, 2009, Varaždin, Croatia: proceeding, Faculty of Organization and Informatics Varaždin, Varaždin, 2009.
[11] National project: Development of Natural Science Competences, No. 3311-08-286011, at the Faculty of Natural Sciences and Mathematics, University of Maribor; supported by Ministry of Education and Sport of Republic of Slovenia and the European Social Fund. 